\title{
Arte, adolescencia y Trabajo Social: Anja, la regidora invisible
}

\author{
Art, adolescence and Social Work: Anja, the invisible manager \\ Libertad GonZÁLEZ ABAD \\ Universidad Complutense de Madrid \\ libertad5@yahoo,es
}

Recibido: 21/06/2015

Revisado: 07/07/2015

Aceptado: 27/11/2015

Disponible on line: 20/01/2016

\begin{abstract}
Resumen
Este artículo nace con la intención de poder analizar las aportaciones del arte, el teatro en este caso, a la práctica del Trabajo Social. Para ello optamos por leer la realidad social en la que intervenimos bajo la lente del construccionismo social. Esto nos ayuda, por un lado, a rescatar el lado social y subjetivo del arte y, por el otro, a recuperar la mirada no patológica del sujeto en la intervención profesional. Así pues, a través de la sistematización de un caso práctico extraído del trabajo con adolescentes en el programa alemán FSJ, recorremos de la mano de una joven llamada Anja, aspectos evolutivos y sociológicos de la adolescencia para abordar, a continuación, algunos puntos de encuentro entre el arte y el trabajo psicosocial. Así el arte será redefinido como un objeto transicional en el que poder trabajar cuestiones relacionadas con la autopercepción, la vinculación, la comunicación y el cambio de conductas como último fin de la actuación profesional. Por último, señalamos las limitaciones y riesgos de la intervención basada en el arte para concluir con una sinopsis final.
\end{abstract}

Palabras clave: arte, adolescencia, trabajo psicosocial.

\begin{abstract}
Abstract: This article has been written with the intention of being able to analyse the contributions of art - theatre, in this case - to the practice of social work. For this purpose, we have chosen to read the social reality in which we intervene through the lens of social constructionism. This helps us to rescue the social and subjective side of art, and, moreover, to recover the depathologization of the subject in professional intervention. Thus, using a practical case taken from work with adolescents in the German FSJ programme, hand-in-hand with a young girl called Anja we trace the developmental and sociological aspects of adolescence in order to later address certain common points of art and psychosocial work. Art will hence be redefined as a transitional object allowing questions to be addressed relating to (self-) perception, attachment, communication and changes in conduct as the ultimate goal of professional action. Lastly, we note the limitations and risks of art-based intervention, in order to conclude with a final synopsis.
\end{abstract}

Keywords: art, adolescence, psychosocial work.

Referencia normalizada: González Abad, L. (2016): «Arte, adolescencia y Trabajo Social: Anja, la regidora visible». Cuadernos de Trabajo Social, 29(1): 63-72.

Sumario: 1. Premisas conceptuales. 2. Metodología. 3. Resultados. 4. Algunas reflexiones sobre el arte como herramienta en el trabajo social. 5. Conclusiones. 6. Referencias bibliográficas.

\section{Premisas conceptuales}

Pensamos que es necesario, antes de iniciar la lectura, de la experiencia que relata este ensayo, plantear brevemente dos cuestiones en torno a dos ejes: la manera como entendemos el arte y la forma de concebir la práctica del Trabajo Social. En referencia al primer punto, coincidimos con el maestro Ernst Hans Gombrich (1987) en afirmar que el arte no es solo algo realizado por el hombre, sino también para el hombre. En este sentido, su aplicación práctica en el campo de lo social se basa en la capacidad creadora inherente a todo ser humano, que le permite elaborar, a partir de lo ya existente, nuevos elementos que se incorporan a la realidad objetiva y, especialmente, a la subjetiva. Es decir, realidad y fantasía están siempre en constante relación, generan una 
ecuación clave, en la que la imaginación se apoya en la experiencia para emerger $\mathrm{y}$, a su vez, la experiencia se apoya en la fantasía para sobrevivir (Vigotsky, 1982).

Ahora bien, ¿de qué manera el arte supone un apoyo, un recurso para el Trabajo Social? A esta pregunta sugerimos dos respuestas breves.

Si partimos de ideas construccionistas y entendemos que el mundo en el que el sujeto se desarrolla no viene dado y se construye, en cambo, a través del lenguaje y las posibilidades que ofrece el entorno, el arte se convierte en un elemento más con el que nutrir y ampliar la realidad en que habita la persona (Berger y Luckmann, 1986; Gergen y Gergen, 2011; Keddell, 2011). Además, observamos que el arte no supone únicamente un apoyo para el usuario en la clásica relación vertical y unidireccional del Trabajo Social, sino que invita a examinar los discursos habituales que envuelven a los técnicos: tanto los que dan cuerpo a las normas sociales y a los intereses políticos, como aquellos en los que ciertas profesiones construyen problemas sociales. En este sentido, y en relación a la segunda cuestión planteada, desde una perspectiva crítica podríamos afirmar que el Trabajo Social, como disciplina, se inscribe en una doble función: vigilar y corregir. Según Foucault (2004), bien a través del castigo, bien a través del magisterio, el profesional trata de abordar la «desviación» del individuo y su impacto en la sociedad. En este acercamiento, del ámbito médico al de la intervención social, parece clara la tendencia a lo patológico del sujeto y de su mundo relacional, dando lugar a una «medicalización de lo social», que en múltiples ocasiones impide promover cambios y transformaciones. Será, pues, a través de la experiencia práctica y su análisis, como pretenderemos poner de relieve la importancia de superar la categorización de las desviaciones, que se basan en esencias de personalidad del sujeto, y dar visibilidad al papel que juega el arte como instrumento de cambio en esta misión.

\section{Metodología}

\subsection{Análisis de casos: la sistematización de la práctica}

Este artículo nace con la intención de responder principalmente a una pregunta:¿Qué aspectos psicosociales son los que podemos trabajar a través del arte con la población adolescente? Es esta pregunta la que incita nuestro estudio y las reflexiones que lo acompañan. Partimos del convencimiento de que el Trabajo Social, por su naturaleza teórica y práctica, ofrece por sí mismo situaciones psicosociales, objeto de estudio, que deben y pueden aprovecharse en términos teóricos. Así, basamos el presente trabajo en el análisis de un caso y en su correspondiente sistematización e interpretación. Con esto pretendemos no sólo ser reflexivos sobre la propia actuación profesional, sino lograr una comprensión global del encuentro entre arte, Trabajo Social y adolescencia, a través de una fotografía completa y contextualizada del mismo (Yin, 2014). Para ello, escogimos el caso de Anja (nombre real autorizado), conscientes de que su complejidad suponía un atractivo a la hora de desarrollar las ideas teóricas posteriores. Hemos obviado los casos extremos de éxito o fracaso evaluados tras el programa, optando por un caso que acordamos denominar «en construcción». Es decir, los procesos de Anja siguen activos y, lejos de ser clasificados, deben ser estudiados. Tras la elección del caso, procedimos a su sistematización, recurriendo a las notas de campo registradas durante el proceso de intervención, así como a las que tomamos durante los procesos reflexivos con el equipo profesional. También las grabaciones de algunas sesiones fueron analizadas por su contenido y sirvieron de base para establecer los principales temas, objeto de estudio. Asimismo, han servido como datos las breves notas tomadas durante una entrevista individual de seguimiento de caso. Cabe señalar que, puesto que la intervención requería una trabajo dinámico entre profesionales y adolescentes, no existe gran cantidad de transcripciones literales del discurso de Anja o sus compañeros, por lo que se ha intentado complementar las transcripciones literales con la creación de un hilo conductor narrativo.

Así pues, presentamos un estudio de caso de carácter inductivo y exploratorio a través del cual lanzaremos algunas hipótesis sobre la forma en que el arte y el Trabajo Social se encuentran en la intervención con adolescentes en situación de riesgo.

\subsection{El caso: Anja, la regidora invisible}

Anja es una joven de 16 años, nacida en un pueblo cercano a Halle. No conoce a su padre. Sus dos hermanas menores están tuteladas por la Ad- 
ministración alemana desde hace dos años. Tienen 7 y 9 años. Ella vive con su madre, una mujer en situación de desempleo que trabaja cuando la oficina de empleo temporal le reclama intermitentemente que lleve a cabo actividades relacionadas con la promoción de productos alimenticios y el mantenimiento doméstico.

Anja narra su historia de manera firme, arrojando datos y fechas. Ha aprendido que lo que está viviendo es «lo mejor para ella» y asume la contradicción que le atraviesa: sentirse afortunada por no ser una Fürsorgerkind (niña tutelada) y la amargura de confirmar que su permanencia en el hogar es a cambio de que se constituya como el pilar de su madre, una mujer que se apoya en ella para poder recuperar a sus otros anhelados hijos: « (...) Mi madre no es una mala madre, pero merece lo que le pasa ...no ha sabido ser responsable [...] mis hermanas las veo de vez en cuando, nos da pena estar separadas, pero es mejor así» (Anja).

$\mathrm{Su}$ vida se nos presenta compleja y repleta de claro-oscuros, recovecos e incógnitas. El informe de derivación dice literalmente que Anja es una persona frágil con unas heridas que, se sobre-entiende, no han cicatrizado.

Más allá de lo que recoja su historia social, la Anja que encontramos nos parece: «una joven adolescente introvertida, observadora, silenciosa y en definitiva de pocas palabras. Mira lejos, quizás perdida, pero siempre presente» (Notas del profesional).

En los primeros días de encuentro, Anja escucha, hace, obedece y cumple. Es como si hubiera aprendido que debe hacer lo que se espera que haga, en según qué contextos. De lo contrario corre el riesgo de caer, al igual que sus hermanas y su madre, en el mundo de los nadies (Galeano, 1993). Está a un paso y lo sabe.

\subsection{El contexto del caso}

Nuestra primera semana de trabajo conjunto se centró principalmente en la creación de grupo. Las dinámicas grupales, el ocio y el aprendizaje por medio de la experiencia constituyeron el núcleo durante esos primeros siete días. Que el teatro se constituyera como el hilo conector entre los participantes, los profesionales, el entorno y la vida de cada uno de los implicados fue un acontecimiento casual y «libremente» elegido por los chicos y chicas del programa. Libremente debe ir entrecomillado, porque no hacerlo su- ponía una falsedad. La filosofía de trabajo de este equipo profesional era que había diversas maneras de alcanzar objetivos psicosociales con las personas. Nuestra obligación era presentar una amplia paleta de posibilidades y mantener el oído atento para captar qué instrumento era el más adecuado para cada grupo humano con el que compartimos experiencias.

Además del arte, tema al que dedicaremos la mayor parte de las reflexiones, estos chicos y chicas vieron en el grupo un espacio en el que hallar su identidad, pudiendo separarse del otro, a la vez que se mantenían relaciones con el mundo exterior. Es lo que ya señalara Winnicott (1953): la capacidad de mantener la vida externa e interna separada y diferenciada, pero estrechamente relacionadas. En este sentido el grupo se convirtió, con el paso de los días, en una especie de objeto transicional, con el que se podían adquirir experiencias relacionales, como sugiere el autor. Era una herramienta capaz de generar situaciones emocionales, cuyo contenido mental, lejos de evaporarse al finalizar, pervivía «como una experiencia y como un referente para cada una de las personas participantes» (Rosell, 1998, p. 104). Como señalábamos anteriormente, la expresión corporal y el teatro, en el caso práctico que exponemos, también se constituyeron como un objeto transicional, concebido a petición de los chicos y chicas, y al servicio de sus necesidades. El grupo podía poseerlo, mutilarlo, adorarlo u odiarlo. Durante estos días no se apropiaron de una obra de arte, sino que del proceso creativo y de la percepción creadora (Winnicott, 1953).

\subsection{El momento evolutivo: adolescencia, construcción de una realidad psicosocial}

Este aspecto de apropiación y uso de algo que ellos habían construido resultaba de vital importancia; pues, más allá de la vida compleja de cada uno de ellos, todos compartían un elemento en común: la etapa evolutiva, eran jóvenes adolescentes.

¿Es la adolescencia un elemento natural de toda sociedad? ¿Existe una adolescencia de estudio, permeable a categorías universales que permita homogeneizar una parcela del desarrollo humano?

Las respuestas han sido y son variadas según lo que la disciplina lea y responda a la pregunta. Sin embargo, para muchos existe hoy en día una 
necesidad de pluralizar: la necesidad de hablar y concebir diferentes «adolescencias» y «juventudes», según la premisa que establece que ambos conceptos son una construcción sociohistórica, cultural y relacional, producto de la sociedad moderna y en permanente cambio y proceso de resignificación (Feixas, 1998; Dávila, 2004). La adolescencia es una construcción social que, si bien puede ser compleja, no siempre ha de ser traumática.

Según las reflexiones recogidas entre otros por Feixas (2006), la adolescencia se instala como noción a principios de siglo XX, cuando de manera natural se prolonga la socialización del infante en instituciones educativas y se reduce considerablemente el tiempo empleado por él en tareas laborales. Se entiende que el individuo necesita un tiempo, libre de responsabilidades, la moratoria psicosocial de Erikson en términos psicológicos, que le permita hacer una transición paulatina hacia la vida adulta.

Por otro lado, para Patiño (2009) entender la adolescencia y la juventud como una etapa vital puede llevar a lecturas lineales, lógicas y acumulativas, que se basan en criterios cronológicos y hormonales que la convierten en una noción universal. Esta aproximación olvida que, si bien la pubertad y los cambios asociados al proceso de desarrollo y maduración biológica de la especie, aunque lo son, «no puede decirse que las significaciones y prácticas que se realizan antes, durante y después de la pubertad sean equivalentes en todos los contextos» (p. 78). Desde esta perspectiva, ¿qué hacer con las disciplinas psicosociales que una parte de sus esfuerzos los dirigen a cubrir necesidades de esa etapa evolutiva?

Para nosotras, es necesario comprender la existencia y, a la vez, la construcción de las adolescencias y debemos obligarnos a pensar en ellas. Significa que no hemos de olvidar en qué contexto se inscribe la construcción de dicha noción y apreciar los efectos que tiene en el sujeto y en el resto de sociedad (Feixas, 1998; Feixas, 2006). Para ello es necesario dejar atrás el paradigma positivista y empírico de la modernidad, no cegarse intentando verificar o falsear ciertas hipótesis, y acercarse a la vida de las personas aceptando la especificidad de cada una de ellas, dejando que sea ésta la que reoriente teoría, técnica y práctica.

Así, pues, sin olvidar estas apreciaciones y desde un punto de vista psicosocial, durante la adolescencia, el individuo experimenta la necesidad de tener una mayor autonomía, de construir una identidad del self que pasa por el inevitable proceso de diferenciación o individuación (Bowen, 1991; Stierlin, 1997). Este proceso necesita la aceptación de una interdependencia que «no solo limita las posibilidades en su proyecto de individuación sino que es la base para alcanzar la autonomía en un cuadro de pertenencia» (González, 2013, p. 331).

Si esta es una de las tareas complejas, que el sujeto debe abordar durante la adolescencia, el contexto posmoderno en el que debe lograrlo la dota de una dificultad añadida. Hoy en día, la noción de adolescente y de joven se asocia a unas connotaciones negativas, tales como: déficit, carencia, anomia y irresponsabilidad. Ante este caos aparente, se promueven contextos cada vez más coercitivos y correctivos que obligan al individuo a actuar en contra de su voluntad, abrazando la generalización y el prejuicio como herramientas de supervivencia. En este contexto, la creatividad del sujeto se desplaza al último lugar, olvidando que es una de las herramientas básicas para descubrir soluciones y alternativas al problema en concreto (Twenlow, Fonagy y Sacco, 2005).

Será, en esta foto inicial un tanto limitante, como con el teatro, la creación escénica, el lenguaje corporal, los gestos, las miradas y el contacto físico con los otros, los chicos y chicas de este artículo descubrirán un idioma en el que ellos mismos inventen el vocabulario, los puntos, las comas y los espacios. Serán los inventores no solo de lo que quieren decir sino de cómo decirlo.

\section{Resultados}

\subsection{Arte: un objeto transicional}

El arte en términos genéricos o, en este caso, la capacidad creativa la entenderán los jóvenes no como un juego — que también lo entenderán así-, sino como un elemento de apoyo que, en su función simbólica, les va a servir para contactar consigo mismos, con los otros y con su entorno, de una manera segura y poco amenazante (Erkolahti y Nyström, 2009). Así pues, el arte añade al espacio grupal - ahora seguro- una dosis extra de posibilidades, en el que cualquier acto, comentario o producto allí creado será acogido sin juicio alguno. De alguna manera, pode- 
mos afirmar, que forma parte de su ADN transgresor (Johnson, 2008).

Dicho esto, volvamos a la protagonista de nuestro artículo. ¿Será para la tímida y distante Anja un espacio poco amenazador? ¿Ofrece el teatro, la expresión corporal, el contacto físico un espacio por sí mismo poco desafiante? El diario de campo recoge que no. No mostró entusiasmo ni tampoco un rechazo patente. Ni para Anja ni para el resto del grupo fue el espacio creativo, un espacio libre de preocupación. Morar en un terreno distinto, de que se desconocen las normas de habitabilidad, resulta muy angustiante en una fase de la vida en la que uno se debe a la misión de formar parte de la masa y treata de encontrar en ella su individualidad. «(...) si se tiene que hacer, por mi está bien, está bien...» (Anja); 《 (...) ¿de verdad tenemos que tocarnos con cualquier parte del cuerpo? ¡venga! ¡por favor! ¡qué estupidez! (J. $5)$; «(...) ya que lo del campeonato de consolas no ha colado... está bien, esto del teatro [risas de complicidad] «(J. 1).

Para Anja, concretamente esta propuesta significaba una de esas cosas que los profesionales decidían y, por lo tanto, había que hacerlo. Y no le faltaba razón; aunque la propuesta fuera de la mayoría de los participantes, los profesionales aceptamos. Decidimos que su decisión era aceptable.

Sin embargo, tras 12 meses de proyecto pudimos comprobar que para Anja, al igual que para cada uno de los participantes, el hecho de trabajar con herramientas artísticas les brindaba la posibilidad de redescubrir el mundo en términos más comprensivos y comprensibles. Así, a través del Proyecto de teatro - llamémosle así- se construyó una realidad paralela, con normas, códigos y roles alternativos que sirvieron como laboratorio experimental para aquellos que lo habitaban por unas horas al día.

Algo interesante de este Proyecto de teatro era que no solo requería actores o actrices. Se apoyaba en las múltiples y diversas capacidades creativas que poseían los chicos y chicas del grupo, aún sin saberlo. Necesitaba guionistas, coreógrafos, músicos, sastres, apuntadores, escenógrafos y público. Ofrecía un abanico de posibilidades, de formas de actuación que trascendían la idea inicial que podía suscitar la palabra teatro.

Durante los 12 meses de intervención, Anja no encarnó la figura de la fantástica actriz revelación ni se descubrió su escondido, pero dester- nillante, sentido del humor. Tampoco resultó una líder innata oculta tras la sombra de una vida difícil ¡ni falta que le hizo! A su estilo, de la mejor manera que sabía, es decir desde la tercera fila, en voz baja y con una sutilidad apabullante se consolidó como la escenógrafa y pensadora de las escenas más expresivas que pudo producir el grupo. Desde el inicio del trabajo con role playing hasta las sesiones de improvisación teatral de más de dos horas en las que participaban todos, Anja dejó claro que había encontrado en eso del teatro una manera de expresar lo que vivía, pensaba y sentía. Pocas veces puso palabras a lo que dijo con el cuerpo de los otros, pero cuando lo hizo, fueron realmente reveladoras.

De alguna manera, tanto los profesionales como los adolescentes aprendimos la importancia de no poner el foco en el producto, sino en el proceso o, como indica Aguirre(2012), en plantear preguntas no sobre la obra artística en sí, sino sobre las miradas que la crean.

\subsection{Percepción: ¿quién soy?}

De este modo observamos que este objeto manipulable implica necesariamente una revisión de la propia percepción del otro y del entorno, que hemos venido narrando. Aquel más cultivado, de clase media, que acostumbra a hacer lo correcto y lo esperado de manera natural se descubrirá desnudo ante sí, cuando tenía que caminar ante sus compañeros y compañeras. Quién acostumbra a caminar sin ser mirado quizás se sienta desnudo, pero también escuchado. A través de la creación de escenas, cuadros, historias de amor, amistad, familia o trabajo (ejes temáticos trabajados durante el año a elección de los participantes) irán descubriendo quiénes son ellos y cómo es el mundo en el que viven.

Anja, como hija «parentalizada» había desarrollado unas habilidades importantes para observar, organizar y hacer con poco, mucho. Sabía leer la complejidad de ciertos capítulos de la vida y había visto, cuando no vivido, de manera prematura la dureza de algunos amores y algunas familias. No se trataba de minimizar o alabar estas experiencias precoces, pero sí de saber que estaban ahí y que podían integrarse como algo positivo en su biografía. Pensamos que Anja, consciente de sus debilidades, pudo devolverse una lectura menos dañada de sí misma de lo que, al fin y al cabo, constituía su biografía. Reconocer en su «parentalización» unos puntos positi- 
vos que eran capaces de devolverle un lugar en la categoría social de chica joven, fue algo que - pensamos - pudo lograr. Precisamente esas habilidades son las que situaron a Anja en la primera fila, en la mente de sus compañeros y compañeras, quienes la requerían y necesitaban para poder ensamblar sus propuestas. Decimos en la mente, porque en lo físico, Anja se mantuvo en la tercera fila. Ahora bien, para el grupo pasó de ser la chica rara-solitaria a ser una suerte de Pina Bausch, adolescente, de la Alemania del Este más invisible.

\subsection{Vinculación: ¿quién eres?}

El espacio transicional, anteriormente mencionado, conlleva la asunción de roles y actitudes distintos de los vivenciados en otros momentos de la vida. Esta alteración del orden previamente establecido implica una serie de encuentros, capaces de acercar a unas personas que fuera del proyecto son antagonistas.

En el grupo de pares, se produjeron acercamientos en general entre personas que, como señalaban algunos adolescentes: «(...)si llega a estar en mi clase le hubiera hecho la vida imposible...»(J. 3): «(...) no tenemos nada que ver... ni si quiera somos del mismo barrio...»( J. 1).

La exploración del sí mismo y de la realidad que ellos percibían se llevaba a término con una libertad corregida y aumentada que hacía del microcosmos grupal un lugar idóneo para recuperar e instaurar relaciones deterioradas o inexistentes (Johnson, 2008).

Ahora, bien, ¿logra el arte romper las desigualdades sociales y de clase, al menos durante el tiempo en el que se convive en el área intermedia de experiencia creativa a la que hacemos referencia? Nuestra práctica hasta ahora lo niega, al menos parcialmente. No es casual que Anja lograra, según sus propias palabras: «(...) una bonita amistad... [con Janda] ... sé que si necesito algo ella está ahí... y yolo mismo... Podemos decir que ella es mi amiga... » (Anja).

Janda (nombre real autorizado) era una joven inmigrante siria que hacía tres meses apenas que había llegado a Alemania con su familia, buscando (y encontrado) asilo político. Estas dos personas se brindaron un apoyo único en su proceso de desarrollo y adaptación. Fue interesante ser testigo de este puente, en el que se consolidaron mutuamente para poder caminar hacia adelante, sabiendo que tenían un punto de retorno seguro y protector, si lo necesitaban. Sin embargo, es curioso que estas dos personas, posiblemente las más dañadas del grupo, encontraran una en la otra el apoyo que buscaban.

Si esta vinculación entre Janda y Anja fue sólo gracias al teatro, lo desconocemos. Es más, muy posiblemente no; pero el hecho de que ambas pudieran ofrecer, a través del proyecto, versiones de sí más completas e incluso inesperadas hizo, sin duda, que el acercamiento y encuentro fueran más seguros y firmes.

Mas este trabajo a través del arte también supone un apoyo para el profesional y su siempre y necesaria alianza terapéutica. Alcanzar una relación basada en la confianza y en la igualdad es difícil, especialmente cuando la percepción del usuario es que entre ellos existe un abismo insalvable, marcado por el conocimiento, el estatus y el poder. Cambiar los roles dicotómicos establecidos entre proveedor-acreedor de conocimiento para pasar a una relación en la que ambas partes fueran ignorantes y sabias por igual (Freire, 1970) no es tarea sencilla ni quizás alcanzable al cien por cien.

En este sentido, poner el foco en cuestiones que no son la demanda inicial ni la categoría social asignada por el técnico social, abre espacios de comunicación y relación al margen del déficit, de lo que no funciona. No es lo mismo buscar el vínculo, partiendo de la carencia, que encontrarlo mientras uno recoge creaciones de las que se siente orgulloso. Uno tiene más ganas de compartir y mostrar aquello que lo posiciona en un lugar diferente al de marginado o fracasado. Para Wright (2008), ofrecer programas comunitarios basados en las artes genera «algo de lo que hablar y algo que compartir» (p. 18), con personas tanto internas como ajenas al grupo. Condimentar las intervenciones sociales con actividades artísticas y creaciones propias ayuda a «despatologizar» la realidad de los participantes. Es una opción en la que el usuario recupera parcelas de poder sobre su vida y en la que también el profesional recupera el poder del Trabajo Social, evitando la dominación burocrática y administrativa de una práctica inevitablemente relacional (Moffat, 2001). En palabras del autor francés Costes (2001): «ni el arte ni el artista curan. Sin embargo, hay un arte de la relación que tiene que inventarse» (p. 92).

Así, Anja usó a sus compañeros para expresar sus pensamientos y emociones $y$, a su vez, se sirvió del profesional y la lectura psicosocial de 
su propuesta teatral para obtener una versión comprensiva de esa escena de su vida.

\subsection{Lenguaje analógico y dialógico: ¿qué digo?}

Esto nos lleva a otra de las fortalezas de los proyectos artísticos-creativos para la intervención social. La comunicación, el lenguaje hace tiempo que se constituyó como el eje del trabajo con las personas. Pero bien sabemos que hay situaciones y momentos vitales en los que las personas expresan verbalmente solo una ínfima parte de sus vivencias. A veces no expresan más porque no quieren; pero en otras, la complejidad de lo que experimentan es tal que resulta difícil traducirlo en palabras. Como señala Rodriguez (2011) es la estructura de cada sujeto la que determina la comprensión e interpretación de una experiencia en particular. Esto explica que, en ocasiones, sea complejo acceder a lo analógico y lo relacional. Para Watzlawick (1997): «la primera consecuencia de un derrumbe en la comunicación suele ser la pérdida parcial de la capacidad para metacomunicarse en forma digital acerca de aspectos relacionales» (p. 2013). Es ahí donde el arte, como instrumento expresivo y comunicativo, tiene una función terapéutica y liberadora. En definitiva, el arte se consolida en lo psicosocial como un medio comunicativo que «ayuda a expresar material complejo de manera sencilla» (Gussak, 2007, p. 446).

El lenguaje que ofrece el trabajo artístico se basa en el juego metafórico; es capaz de concretizar lo abstracto; ofrece una imagen determinada, clara y eficaz que, sin embargo, transmite una sensación multidimensional representativa de la complejidad real.

En el caso de Anja, recordamos el momento en el que se abordaron los tipos de familia que cada uno de los chicos y chicas creían que había. El pasillo largo oscuro, con puertas a ambos lados pero todas cerradas, plasmado por Anja desde su asiento de regidora, daba cuenta de una familia que definieron con mil palabras, sin llegar a estar nunca satisfechos con su enunciado. Sin embargo, la imagen evocada fue renombrada en posteriores debates, aludiendo a ella como «la familia del pasillo»».

Y es que, como ya señalara Winnicott (1982) los objetos transicionales permiten la activación y desarrollo del pensamiento abstracto, ampliando el mundo concreto y accediendo al universo de valoraciones y significados.

\subsection{Cambio de conductas: ¿qué pienso?}

No hay que olvidar que, «a menudo nos vemos atrapados entre la intención de cambiar conductas y la evidencia de ofrecer recursos» (Rodríguez, 1992, p. 82). En el trabajo con la adolescencia podría pensarse que las conductas que han de cambiar son aquellas disruptivas, las que molestan, las que - como dice su nombreproducen rupturas bruscas, especialmente con el orden establecido; pero - como dice una compañera - no todo en la vida consiste en dar portazos.

En este sentido, tal y como señala Brignoni (2012), durante la adolescencia, lo que a uno le resulta más complicado es reconocer los espacios y las personas disponibles para actuar ante llamadas de ayuda y apoyo. Jugar con la soledad y desconexión que acompaña la adolescencia forma parte de nuestro proceso modificador de conductas.

Para que los cambios sean útiles es necesario «escuchar el marco de referencia interno, su mundo de significado» (Arija, 2003, p. 64). Esto quiere decir que el profesional debe atreverse a asistir con un oído virgen al primer encuentro con los chicos y chicas. No dar por sentado el pensamiento o la emoción de las personas, de acuerdo con las categorías diagnósticas asignadas a sus trayectorias vitales; es una de las llaves que abren la puerta de la co-construcción del caso con el adolescente. Los profesionales necesitamos al otro para intervenir; y necesitar al otro pasa por descubrir, y no por confirmar, las hipótesis de trabajo conjuntamente, ni en establecerlas por adelantado.

El cambio de conducta del chico o chica vendrá por el vínculo generado en un espacio que le permita percibirse y percibir el exterior como algo merecedor de su cambio.

Dice el maestro Cirillo (1998): se trata de lograr que piensen más y actúen menos. Lo cierto es que esto es siempre un requisito para activar procesos reflexivos y de mentalización. La pregunta es si con personas como Anja, que posiblemente no dejen de pensar durante todo el día, esto no incurre en una contradicción. Para nosotros, el pensamiento de Anja no es puramente reflexivo, sino que combina una sucesión de pensamientos que repasan los problemas de hoy, las necesidades de mañana, y las soluciones inmediatas, pero que establecen como base la realidad dada, concebida de manera monolítica, de 
consecuencia lineal y fuera de su control y comprensión.

Mi madre fue abandonada por mi padre, no llegué a conocerlo. Supongo que aguantar a mi madre era imposible y más con un bebé en medio (...) así que se quitó de en medio. No le culpo, solo me hubiera gustado conocerlo (Anja).

$\mathrm{Su}$ pensamiento y percepción de la realidad están sostenidos por pilares que sitúan su historia de vida en un marco de culpables, victimas, verdugos y damnificados, definidos en categorías morales de buenos y malos, que limitan su construcción más allá de estos parámetros.

En este marco de indefensión, el arte ofrece la posibilidad de abandonar el papel vulnerable del usuario para apoderarse de una actitud activa que anima a hacerse responsable de sus pensamientos, palabras, actos y creaciones (Johnson, 2008). Tal y como recogen George, Coleman y Barnoff (2010): «más allá de acceder a algo concreto, lo creas tu mismo» (p. 20).

En cualquier caso, lo que se logra es que actúen lo que piensan en un contexto seguro, sostenido por dos herramientas: el grupo y el proyecto creativo. Es un espacio en el que pueden probar otras formas de relación, otros «yoes» con la seguridad de que, si no dan los resultados esperados, no dejarán una huella imborrable en la biografía de quien lo haga. Aquello que en el escenario no funcione puede ser desechado (al menos de momento) al tiempo que se guarda en el disco duro de experiencias relacionales.

De vuelta a la práctica, la lluvia de ideas, la defensa de unas, la crítica de otras, fueron cuestiones que pasaron de ser peliagudas al inicio, al pan de cada día del proyecto de teatro. De alguna manera, se iniciaron procesos reflexivos en los que los chicos y chicas eran capaces de relativizar su propio punto de vista y al menos escuchar otros alternativos (Lanza, 2011). Este apoderamiento de los procesos relacionales, que es lo que al fin y al cabo son, pasó por un también inesperado grado de responsabilidad. Quizás este aspecto fue el que más tensión generó, pues, qué difícil es respetar lo ajeno cuando lo propio se siente como parte intrínseca de uno mismo. Lo realmente llamativo, y pensamos que es la gran aportación en este apartado de análisis, fue que los chicos y chicas experimentaron un grado de control sobre sus vidas que les reportaba ade- más de una imagen de sí mismo distinta de la que ya conocían, una satisfacción vital serena y confiada en un momento evolutivo que va acompañado de cambios y frustraciones a veces de difícil comprensión.

Al principio mucha vergüenza, no me gustaba y no quería. Ahora sé que si me preguntan puedo contestar [en referencia a la hipotética entrevista de trabajo]...lo que sea! Quizás hasta me lo invente, pero no me quedaré en blanco! [risas] (J.4)

(...) en el escenario nunca, nunca [...] desde abajo ya es otra cosa...tengo ideas y las digo... si a ellos les viene bien, pues bien! [Tímida sonrisa] (Anja).

\section{Algunas reflexiones sobre el arte como he- rramienta para el Trabajo Social}

A lo largo de estas páginas hemos analizado y teorizado sobre un caso de intervención en el que el uso del arte juega un papel importante como facilitador para el logro de objetivos sociales. Sin embargo, quisiéramos compartir algunas notas que durante estos años de proyecto fueron debatidas por los profesionales implicados.

Por un lado, creemos necesario también señalar que el arte debe ser un instrumento al servicio de la intervención. Esta obviedad a menudo puede olvidarla o pasarla por alto el equipo profesional, aunque goce de un alto compromiso con la profesión. No son pocas ocasiones en las que nos hemos cuestionado nuestra propia práctica basada en el arte. ¿Por qué optamos por una metodología artística o creativa? ¿Para quién planificamos la intervención? ¿Qué necesidades estamos satisfaciendo? ¿Quién ocupa el centro de nuestra propuesta? Parecen preguntas sencillas, pero a menudo nos hemos dado cuenta de que implementar estas prácticas sacia dos necesidades latentes del profesional. En primer lugar, existe el peligro de plantear un proyecto que acabe convirtiéndose en un espacio de proyección del profesional a través del cual subsanar talentos inacabados o éxitos despreciados. En segundo lugar, la necesidad de cambiar unas prácticas cada vez más burocratizadas que apenas tienen en cuenta al sujeto (y se centran en el formulario) puede hacer que el énfasis puesto en el cómo, relegue a un segundo plano cuestiones tan importantes como el qué, para qué y por qué. Plantear proyectos que metodológicamente sean novedosos, flexibles y necesarios no debe signi- 
ficar olvidar la reflexión epistemológica y ontológica del Trabajo Social.

Por el otro, y como complemento a los resultados aquí presentados, compartimos con Costes que, aunque el arte pueda ser una vía de alivio y desahogo, no es por si solo una herramienta de cambio. Mas, sí es una vía de expresión de emociones y significados privilegiada frente al lenguaje verbal que puede ser usada por el profesional para devolver una imagen del sujeto más comprensible y por tanto más habitable. En este sentido, un estudio detallado sobre los factores terapéuticos en los contextos de intervención con arte, sería necesario para poder discutir esta cuestión de manera científica.

\section{Conclusiones}

Como síntesis del artículo podríamos afirmar que el arte en un contexto grupal es capaz de impulsar cuatro aspectos fundamentales. En primer lugar, si se entiende como un objeto transicional, representa un vehículo con el que se alcanza la individuación necesaria para desarrollar una vida autónoma. En segundo lugar, el arte ofrece la posibilidad de comenzar procesos vinculares, logrando subsanar la distancia que pueda existir entre profesional y usuario, determinada por el conocimiento, el estatus y el poder. Por otra parte, el arte aparece como una excusa idónea para desposeer de patología los procesos de intervención y fomentar la adquisición de conductas y actitudes que favorezcan un desarrollo personal mejor. Por último, pero también esencial, el arte se utiliza como una alternativa al lenguaje digital capaz de extraer significados relacionales y analógicos que no siempre logra expresar la palabra.

No obstante, mientras se escribía este artículo multitud de nuevas preguntas han ido surgiendo sobre el tema del arte y el Trabajo Social. Nos preguntamos qué puede hacer el arte por el Trabajo Social, por su educación y por su reactivación en la vertiente más crítica y potenciadora. Queda mucho por probar, compartir, analizar y reformular. Este artículo ha pretendido no solo señalar los ámbitos en los que el arte se descubre como un eficaz aliado, sino que ha aspirado a devolver una idea de intervención flexible y coconstruida con el sujeto que, sin embargo, no olvide la importancia de la teorización y su necesario cuestionamiento fundamentado. En definitiva, nos sumamos a la idea de Berardi cuando afirma que «la intensificación del ritmo de explotación de los cerebros ha colapsado nuestra sensibilidad» y por tanto requiere «un nuevo tipo de acción política capaz de tocar la esfera profunda de la sensibilidad mezclando arte, activismo y terapia» (Público, 29.01.2011).

\section{Referencias bibliográficas}

Aguirre, I. (2012). Hacia una nueva narrativa sobre los usos del arte en la escuela infantil. Instrumento. Revista de Estudo e Pesquisa em Educação, 14(2), 161-173.

Arija, B. (2003). Trabajo Social y Creatividad. Una herramienta alternativa para los procesos de acompañamiento. Trabajo Social Hoy, 40, 57-79.

Berger, P. L. y Luckmann, T. (1986). La construcción social de la realidad. Madrid: Amorrortu.

Bowen, M. (1991). De la familia al individuo: la diferenciación del sí mismo en el sistema familiar. Barcelona: Paidós.

Brignoni, S. (2012). Pensar las adolescencias. Barcelona: UOC

Cirillo, S. (1998). Intervenciones Sistémicas en contextos no clínicos. Revista Systémica, 4-5, 15-26.

Costes, P. (2001). L'art ne soigne pas. Questionnement sur l'art-thérapie en atelier de poterie. Le sociographe, 6, 87-92.

Dávila, O. (2004). Adolescencia y juventud: De las nociones a los abordajes. Ultima Década, 21, 83-104.

Erkolahti, R. y Nyström, M. (2009). The prevalence of transitional object use in adolescence: Is there a connection between the existence of a transitional object and depressive symptoms? European Child \& Adolescent Psychiatry, 18(7), 400-406. doi:10.1007/s00787-009-0747-7

Feixas, C. (2006). Generación XX. Teorías sobre la juventud en la era contemporánea. Revista Latinoamericana De Ciencias Sociales, Niñez y Juventud, 4(2).

Feixas, C. (1998). De jóvenes, bandas y tribus: Antropología de la juventud. Barcelona: Ariel.

Freire, P. (1978). Pedagogía y acción liberadora. Madrid: Zero.

Foucault, M. (2004). Vigilar y castigar: Nacimiento de la prisión (33 ${ }^{\mathrm{a}}$ ed. en español). México D.F.: Siglo Veintiuno. 
Galeano, E. (1993). El libro de los abrazos. Madrid: Siglo XXI

George, P., Coleman, B. y Barnoff, L. (2010). Stories from the Field: Practicing Structural Social work in Current times: Practitioners" Use of Creativity. Critical Social Work, 11(2), 13-27.

Gergen, K.J. y Gergen, M.M. (2011). Reflexiones sobre la construcción social. Barcelona: Paidós.

Gombrich, E. (1987). Historia del Arte. Madrid: Alianza.

González Abad, L. y Mitteldeutschland Diakonie-Alemania. (2013). Intervención con adolescentes en Alemania: El grupo como espacio reflexivo. Cuadernos de Trabajo Social, 26 (2), 327-336.

Gussak, D. (2007). The Effectiveness of Art therapy in Reducing Depression in Prison . International Journal of Offender therapy and comparative Criminology, 51(4), 444-460.

Johnson, L.M. (2008). A Place for art in Prison: Art as a Tool for Rehabilitation and Management. The Southwest Journal of Criminal Justice, 5(2), 100-120.

Keddell, E. (2011). A constructionist approach to the use of arts-based materials in social work education: Making connections between art and life. Journal of Teaching in Social Work, 31(4), 400414. doi:10.1080/08841233.2011.597678

Lanza, G. (2011). Mentalización: aspectos teóricos y clínicos. En $12^{\circ}$ Congreso Virtual de Psiquiatría. Interpsiquis.

Moffat, K. (2010). Vigilancia y gobierno del receptor de bienestar. En A.S.Chambon, A.Irving y L.Epstein (eds.), Foucault y el trabajo social (pp.315-343). Granada: Maristán

Patiño, J.F. (2009). La juventud: Una construcción social-histórica de occidente. Youth: A western social-historical construction. Revista Guillermo De Ockham, 7(2).

Público (2011). Entrevista a Franco Berardi. Disponible en: http://blogs.publico.es/fueradelugar/238/ la-sensibilidad-es-hoy-el-campo-de- batalla-politico (Consultado el 30 de abril de 2015)

Rodríguez, A. (2011). ¿Hacia una mirada integradora en la práctica de la intervención socio-familiar. En I Congreso Internacional sobre la construcción disciplinar del Trabajo Social a propósito del nuevo Grado. Bilbao.

Rodríguez, A. (1992). La intervención psicosocial: individuo, grupo y familia. En VII Congreso Estatal de diplomados en trabajo social y asistencia social: La intervención profesional en la Europa sin fronteras (pp.81-87). Barcelona.

Rossell, T. (1998). Trabajo Social de grupo: grupos socioterapéuticos y socioeducativos. Cuadernos de Trabajo Social, 11, 103-122.

Stierlin, H. (1997). El individuo en el sistema. Psicoterapia en una sociedad cambiante. Barcelona: Herder.

Twemlow, S., Fonagy, P. y Sacco, F. (2005). A developmental approach to metalizing communities: I.A. model for social change. Bulleting of the Menninger Clinic, 69(4), 265-281.

Vigotsky, L. (1982). La imaginación y arte en la infancia. Madrid: Akal.

Watzlawick, P., Bavelas, J. B. y Jackson, D.D. (1997). Teoría de la comunicación humana: Interacciones, patologías y paradojas. Barcelona: Herder.

Winnicott, D.W. (1953). Transitional objects and transitional phenomena. International Journal of Psycho-Analysis, 34, 89.

Winnicott, D. W. (1982). Realidad y juego. Barcelona: Gedisa.

Wright, R., John, L., Alaggia, R., Duku, E. y Morton, T. (2008). Do Community Arts Programs Promote Positive Youth Development?. Critical Social Work. Recuperado de: http://www.uwindsor. $\mathrm{ca} /$ criticalsocialwork/do-community-arts-programs-promote-positive-youth-development (Consultado el 8 de enero 2012)

Yin, R. (2014) Case Study Research: Design and Methods. (5 edición).Thousand Oaks, CA: Sage. 